\title{
Resilience Under Military Operational Stress: Can Leaders Influence Hardiness?
}

\author{
Paul T. Bartone \\ Industrial College of the Armed Forces \\ National Defense University
}

\begin{abstract}
Although many people suffer physical and mental health decrements following exposure to stress, many others show remarkable resilience, remaining healthy despite high stress levels. If the factors that account for resilience can be clearly identified and understood, perhaps resilience can be enhanced even for those most vulnerable to stress. One potential pathway to resilience is personality hardiness, a characteristic sense that life is meaningful, we choose our own futures, and change is interesting and valuable. This article applies this hardiness concept to the context of military operational stress, and argues that highly effective leaders can increase hardy, resilient responses to stressful circumstances within their units. I discuss the nature of stress in modern military operations, and briefly review relevant hardiness theory and research. Three sets of considerations lead to the proposition that hardy leaders can indeed increase hardy cognitions and behaviors in groups. These considerations concern (a) the likely underlying mechanisms of hardiness, which have to do with how experiences get interpreted and made sense of; (b) relevant theoretical positions on leader social influence, including transformational leadership and path-goal leader theory; and (c) several empirical studies that have shown indirect support for a hardy leader influence process. A case vignette is provided to illustrate how leaders might increase hardy cognitions, attitudes, and behaviors within their organizations during highly stressful operations. This potential for leaders to boost hardiness as a pathway to resiliency in groups under stress merits further active investigation.
\end{abstract}

Military operations across the entire range of conflict expose military personnel (and increasingly, contract workers) to a multitude of stressors. These stressors can lead to a variety of negative health consequences, both physical and mental, for

Correspondence should be addressed to Paul T. Bartone, Colonel, U.S. Army, Professor of Behavioral Sciences, Industrial College of the Armed Forces, National Defense University, Ft. McNair, Washington, DC 20319-5062. E-mail: bartonep@ndu.edu 
some exposed individuals. For example, Hoge et al. (2004) recently reported that up to $17 \%$ of U.S. veterans of the Iraq conflict reported symptoms of major depression, anxiety, or posttraumatic stress disorder (PTSD). However, a point that is often neglected in studies of this kind is that most exposed individuals appear to respond with remarkable resiliency to stress, and this includes very severe or traumatic stress (Bonanno, 2004). For example, most survivors of the September 11,2001 , attack on the Pentagon appear to have adjusted extremely well to this acutely stressful event, with no formal mental health intervention other than practical support provided in the aftermath (Ritchie, Leavitt, \& Hanish, 2006). Similarly, as pointed out by Wessely (2005), the vast majority of Londoners responded to the July 2005 terrorist strikes on the London public transit system not with psychopathology, but with resilience. One examination of historical events during World War II also shows the same pattern of broad public resilience, rather than breakdown in the face of the Nazi German bombings of London that killed 40,000 people (Jones, Woolven, Durodie, \& Wessely, 2004).

What accounts for such resiliency? If the factors or pathways that lead to human resiliency under stress were better understood, perhaps some of these resiliency factors could be developed or amplified in those who are initially low in resilience, and more vulnerable to stress. Such an approach now seems even more important, given the generally recognized failure of postdisaster psychological interventions such as critical incident stress debriefing (Mitchell \& Everly, 2000) to make any positive difference for those receiving them (van Emmerik, Kamphuis, Hulsbosch, \& Emmelkamp, 2002). Worse, in many cases such interventions appear to increase rather than decrease the incidence of later psychological problems (Wessely, 2005). This article focuses attention on personality hardiness, one of several potential "pathways to resilience" posited by Bonanno (2004). Based on both theoretical and empirical grounds, I argue that leaders in military units may well be able to foster increases in the kinds of cognitions and behaviors that typify the high-hardy person's response to stressful circumstances.

It is useful to begin by describing the nature of the stressors encountered by troops in modern military operations. Following this, the hardiness construct is explained in some detail, including both theoretical background and some empirical findings showing that hardiness serves to buffer or moderate the ill effects of stress. I suggest that the primary underlying mechanism in the hardiness-resiliency process involves how stressful experiences get interpreted or made sense of in the context of one's entire life experience. Several theoretical positions support the view that leaders may influence this process in work groups such as military units. High-hardy leaders may facilitate positive coping with stress by shaping the shared understandings of stressful events and experiences within the group in a positive and constructive direction. Although this stands now as a theoretical proposition for future research to evaluate more fully, several studies already provide indirect support for this hardy leader influence process. To clarify how this process might 
occur in military groups, a brief case report is presented of a U.S. Army unit deployed to the Middle East.

\section{THE NATURE OF STRESSORS IN MODERN MILITARY OPERATIONS}

Military operations always entail stressors of various kinds for the troops involved. Historically, the extreme stressors of combat and all-out war have received the greatest attention. However, military operations in the post-Cold War era bring additional challenges and stressors. For one thing, as the number of peacekeeping, peacemaking, humanitarian, and other kinds of operations increases, while military organizations shrink in size with the shift to all-volunteer forces, units are deploying more frequently. Increased deployments entail other stressful changes in military units as well, such as an increased number (and intensity) of training exercises, planning sessions, and equipment inspections, all of which increase the workload and pace of operations (Castro \& Adler, 1999). Furthermore, more frequent deployments also involve more family separations, a recognized stressor for soldiers (Bell, Bartone, Bartone, Schumm, \& Gade, 1997).

One obvious way to reduce the stress associated with military operations is to lessen the frequency and duration of deployments. Although this may be a sensible policy approach in principle, it is not always possible given political and strategic realities and limited resources. The same is true in other occupations and contexts. For example, following the September 11th terrorist strike on the World Trade Center, fire, police, and other emergency personnel necessarily maintained continuous operations around the clock with the goal of locating possible survivors, as well as restoring essential services to the affected areas. As this is written, thousands of disaster response workers are currently working to rescue victims and restore basic services in New Orleans and surrounding areas ravaged by Hurricane Katrina in August 2005. In situations such as this, continuous operations and extreme efforts are necessary to save lives; easing the pace of work is generally seen as an unacceptable (if not unethical) compromise. So, when reducing stressful operations or activities is not an option, what can be done to minimize or counter the stressors associated with such operations? In particular, is there anything that leaders can do to facilitate healthy coping with operational stress? To answer this question with respect to the military case, it helps to have a clearer understanding of the nature of the stressors encountered by soldiers on modern military deployments. What is it about modern military deployments that is stressful for those performing them? Extensive field research with U.S. military units deployed to Croatia, Bosnia, Kuwait, and Saudi Arabia from 1993 through 1996, including interviews, observations, and survey data, aimed to identify the primary sources of stress for soldiers on operations. This work led to the identification of five primary psychological stress dimensions in 
modern military operations (Bartone, 2001; Bartone, Adler, \& Vaitkus, 1998). These are isolation, ambiguity, powerlessness, boredom, and danger. Today, the increased frequency and pace of deployments for U.S. forces and the long work hours and days that these deployments entail (Castro \& Adler, 1999) merit the inclusion of another factor, probably best described as workload or deployment stress. These dimensions are summarized in Table 1 and further elaborated next.

\section{TABLE 1}

Primary Stressor Dimensions in Modern Military Operations

\begin{tabular}{|c|c|}
\hline Stressor & Characteristics \\
\hline 1. Isolation & $\begin{array}{l}\text { Remote location } \\
\text { Foreign culture and language } \\
\text { Distant from family and friends } \\
\text { Unreliable communication tools } \\
\text { Newly configured units, do not know your coworkers }\end{array}$ \\
\hline 2. Ambiguity & $\begin{array}{l}\text { Unclear mission or changing mission } \\
\text { Unclear rules of engagement } \\
\text { Unclear command or leadership structure } \\
\text { Role confusion (what is my job?) } \\
\text { Unclear norms or standards of behavior (what is acceptable here and } \\
\text { what is not?) }\end{array}$ \\
\hline 3. Powerlessness & $\begin{array}{l}\text { Movement restrictions } \\
\text { Rules of engagement constraints on response options } \\
\text { Policies prevent intervening, providing help } \\
\text { Forced separation from local culture, people, events, and places } \\
\text { Unresponsive supply chain - trouble getting needed supplies and repair } \\
\text { parts } \\
\text { Differing standards of pay, movement, behavior, etc., for different units } \\
\text { in area } \\
\text { Indeterminate deployment length—-do not know when we are going } \\
\text { home } \\
\text { Do not know or cannot influence what is happening with family back } \\
\text { home }\end{array}$ \\
\hline 4. Boredom (alienation) & $\begin{array}{l}\text { Long periods of repetitive work activities without variety } \\
\text { Lack of work that can be construed as meaningful or important } \\
\text { Overall mission or purpose not understood as worthwhile or important } \\
\text { Few options for play and entertainment }\end{array}$ \\
\hline 5. Danger (threat) & $\begin{array}{l}\text { Real risk of serious injury or death, from: } \\
\text { Enemy fire, bullets, mortars, mines, explosive devices, etc. } \\
\text { Accidents, including "friendly fire" } \\
\text { Disease, infection, toxins in the environment } \\
\text { Chemical, biological, or nuclear materials used as weapons }\end{array}$ \\
\hline 6. Workload & $\begin{array}{l}\text { High frequency, duration, and pace of deployments } \\
\text { Long work hours and/or days during the deployments } \\
\text { Long work hours and/or days in periods before and after deployments }\end{array}$ \\
\hline
\end{tabular}


Isolation

Soldiers deploy to remote locations, far away from home, separated from their families, frequently without good tools or methods for communicating. They find themselves in a strange land and culture, often surrounded by coworkers who are new to them, as the deployed unit was specially configured for a particular mission. They feel isolated and alone.

\section{Ambiguity}

Often in modern military operations, the mission and rules of engagement are unclear, there are multiple missions that are in conflict, or the mission changes over time. The role and purpose of the soldier may be similarly unclear. Confusion and mystery in the command structure adds to this uncertainty (who is in charge of what?). Lack of understanding of host nation language and cultural practices, and how these impact on deployed forces, further adds to the uncertainty (which norms and practices are acceptable in the host culture, and which are not?). This uncertainty can also pertain to other national contingents in a multinational coalition force.

\section{Powerlessness}

Security and operational concerns (e.g., "force protection") often lead to movement restrictions; for example, soldiers are not allowed to leave their base camp. Soldiers may also be unable to interact with the local populace, and are prevented from doing the things they are used to doing (e.g., running or jogging for exercise, displaying their home country's flag), and may also face a variety of restrictions on dress and behavior. They have few choices. Movement and communication restrictions also prevent soldiers from learning about local culture and language, and resources that might be available locally, adding to their sense of powerlessness. They may also observe soldiers from other branches or national contingents operating with different rules and privileges in the same environment, but have no explanation for these different standards. And soldiers may see local people in need of help—wounded, ill, hungry, or despairing — but be unable to give assistance due to movement and contact rules and regulations. ${ }^{1}$

\section{Boredom}

Modern military missions frequently involve long periods of "staying in place," often without significant work to do. As the weeks and months tick by, soldiers start

\footnotetext{
${ }^{1}$ Others have noted the significance of a sense of powerlessness in peacekeeping operations. For example, Weisaeth and Sund (1982) found that in Norwegian soldiers serving in Lebanon under the UNIFIL United Nations peacekeeping mission, the feeling of being powerless to act or intervene was a main contributor to posttraumatic stress symptoms.
} 
to get bored. To some degree, this can be countered by providing more entertainment and sports activities for soldiers. However, the real problem of boredom seems to result from lack of meaningful work or constructive activities in which to engage. Daily tasks often take on a repetitive dullness, with a sense that nothing important is being accomplished.

\section{Danger}

This dimension encompasses the real physical dangers and threats that are often present in the deployed environment, threats that can result in injury or death. Things like bullets, mines, bombs, or other hazards in the deployed setting are included here, as well as the risk of accidents, disease, and exposure to toxic substances. In current U.S. and coalition operations in Iraq and Afghanistan, this includes many hidden dangers such as suicide bombers, snipers, and improvised explosive devices (IEDs). This source of stress can be direct, representing threats to oneself, or indirect, representing threats to one's comrades. Exposure to severely injured or dead people, and the psychological stress this can entail, is also considered under this stress dimension.

\section{Workload}

This factor represents the increasing frequency, length, and rapid pace of deployments that many military units are encountering. Also, most deployments are characterized by a 24-hr, 7-day-a-week work schedule in which soldiers are always on duty, with no time off. Work-related sleep deprivation is often a related feature. Training and preparation activities in the period leading up to a deployment also usually entail a heavy workload and extremely long days. The same is generally true for military units returning home from a deployment, who must work overtime to assure that all vehicles and equipment are properly cleaned, maintained, and accounted for.

It is important to remember that although these major dimensions of stress on modern military operations are discussed as six distinct factors, in practice they overlap and interact in multiple ways (Bartone, 2001; Bartone et al., 1998). The next question is what tools, strategies, or coping mechanisms can be applied to increase resiliency or resistance to these stressors, both at the individual and unit levels. Some authors have suggested that unit cohesion is a powerful influence on unit resiliency under stress (Ingraham \& Manning, 1981; Paton, 1997), and that leadership can also play an important role (Kirkland, Bartone, \& Marlowe, 1993; Watson, Ritchie, Demer, Bartone, \& Pfefferbaum, 2006). In what follows I focus attention on the personality dimension of hardiness, and suggest how leaders might utilize this construct to increase individual and group resiliency under stress. 


\section{PERSONALITY HARDINESS}

In considering the question of what leaders can do to facilitate healthy coping with the stress of military operations, it is useful to take a closer look at what hardiness is, and consider how it might operate as a stress resiliency factor. Conceptually, hardiness is a personality dimension that develops early in life and is reasonably stable over time, although amenable to change and probably trainable under certain conditions (Kobasa, 1979; Maddi \& Kobasa, 1984). Hardy persons have a high sense of life and work commitment, a greater feeling of control, and are more open to change and challenges in life. They tend to interpret stressful and painful experiences as a normal aspect of existence, part of life that is overall interesting and worthwhile.

The concept of hardiness is not new. It is theoretically grounded in the work of existential philosophers and psychologists such as Heidegger (1986), Frankl (1960), and Binswanger (1963), and involves the creation of meaning in life, even life that is sometimes painful or absurd, and having the courage to live life fully despite its inherent pain and futility. It is a global perspective that affects how one views the self, others, work, and even the physical world (in existential terms, Umwelt, the "around" or physical world; Mitwelt, the "with" or social world; and Eigenwelt, the world of the self or me). As early as 1967, using somewhat different terms, Maddi outlined the hardy personality type and contrasted it with the nonhardy "existential neurotic." He used the term ideal identity to describe the person who lives a vigorous and proactive life, with an abiding sense of meaning and purpose, and a belief in his own ability to influence things.

Since Kobasa's (1979) original report on hardiness and health in executives, an extensive body of research has accumulated showing that hardiness protects against the ill effects of stress on health and performance. Studies with a variety of occupational groups have found that hardiness operates as a significant moderator or buffer of stress (e.g., Bartone, 1989; Contrada, 1989; Kobasa, Maddi, \& Kahn, 1982; Roth, Wiebe, Fillingim, \& Shay, 1989; Wiebe, 1991). Hardiness has also been identified as a moderator of combat exposure stress in Gulf War soldiers (Bartone, 1993, 1999a, 2000). Personality hardiness has emerged as a stress buffer in other military groups as well, including U.S. Army casualty assistance workers (Bartone, Ursano, Wright, \& Ingraham, 1989), peacekeeping soldiers (Bartone, 1996; Britt, Adler, \& Bartone, 2001), Israeli soldiers in combat training (Florian, Mikulincer, \& Taubman, 1995), Israeli officer candidates (Westman, 1990), and Norwegian Navy cadets (Bartone, Johnsen, Eid, Brun, \& Laberg, 2002).

Figure 1 shows results from a study on hardiness, combat stress, and PTSD symptoms in U.S. active duty soldiers who fought in the Gulf War (Bartone, 2000). This figure shows the typical, and rather robust interaction of hardiness and stress, wherein it is under high-stress conditions that the resiliency effects of hardiness are most apparent. In this study, high-hardy U.S. Army soldiers exposed to combat 


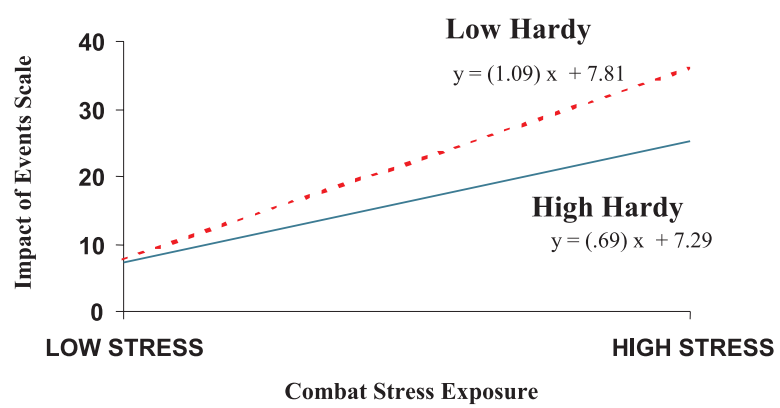

FIGURE 1 Gulf War combat stress exposure predicting Impact of Events Scale scores for low and high hardy groups, active duty sample. Displays Hardy $\times$ Combat Stress Exposure interaction $(p<.0001)$ in regression model, $N=824$ active duty, unstandardized betas used to map regression lines. Reprinted from Bartone (2000). Used with permission.

stress in the Gulf War showed significantly fewer traumatic stress symptoms (as assessed by the Impact of Events Scale; Horowitz, Wilner, \& Alvarez, 1979).

\section{PERSONALITY HARDINESS AS A FRAMEWORK FOR UNDERSTANDING POSITIVE LEADER INFLUENCE}

How does hardiness operate to increase resiliency to stress? Although the underlying processes are still not clear, a critical aspect of the hardiness resiliency mechanism likely involves the interpretation, or the meaning that people attach to events around them and their own place in this world of experiences. High-hardy people typically interpret experience as (a) overall interesting and worthwhile; (b) something they can exert control over; and (c) challenging, presenting opportunities to learn and grow. It seems likely that in organized work groups such as the military, this meaning-making process is something that leaders can have considerable influence over. Military units by their nature are group oriented and highly interdependent. The typical tasks and missions are group ones, and the hierarchical authority structure frequently puts leaders in a position to exercise substantial control and influence over subordinates. By the policies and priorities they establish, the directives they give, the advice and counsel they offer, the stories they tell, and perhaps most important the examples they provide, leaders may indeed alter the manner in which their subordinates interpret and make sense of their experiences. Some empirical support for this notion comes from a study by Britt et al. (2001), who found (using structural equation modeling) that hardiness increases the perception of meaningful work, which in turn increases the perception of positive benefits associated with a stressful military deployment to Bosnia. 
Many authors have commented on how social processes can influence the creation of meaning by individuals. Notable examples include Berger and Luckmann (1966) on the social construction of reality, Janis (1982) on groupthink, and Weik (1995) on the process of sensemaking in organizations. Even Allport (1985), the distinguished American personality psychologist, viewed individual meaning as often largely the result of social influence processes. It would seem that peers, leaders, indeed the entire unit or organizational culture can influence how experiences get interpreted. This leads to what we can term the hardy leader influence hypothesis: Leaders who are high in hardiness themselves exert influence on their subordinates to interpret stressful experiences in ways characteristic of high-hardy persons.

\section{RESEARCH SUPPORTING THE HARDY LEADER INFLUENCE HYPOTHESIS}

Data from several studies with cadets in training to be military officers lend support to the notion that leaders high in hardiness may influence subordinates to think and behave in more hardy or resilient ways. To measure hardiness, these studies used a 15-item scale that (a) includes both positively and negatively keyed items; (b) covers the three hardiness facets of commitment, control, and challenge; and (c) shows excellent validity and reliability (Bartone, 1995, 2000; Bartone \& Snook, 2000). This measure is a shortened version of the Dispositional Resilience Scale (DRS; Bartone et al., 1989) identified by Funk (1992) in his review of hardiness theory and research as the best available tool for assessing hardiness. Also using the DRS hardiness measure, Sinclair and Tetrick (2000) found that hardiness operates independently of neuroticism (Funk \& Houston, 1987), and that the theoretical structure of three facets (commitment, control, and challenge) nested beneath a superordinate hardiness construct is supported by confirmatory factor analysis.

In the first cadet study, the short hardiness scale was administered to a single West Point cohort $(N=435)$ during spring of their senior (fourth and final) year at the academy. Leader performance was assessed with military development (MD) grades, which are assigned to cadets at the end of each academic semester at West Point. These grades represent an average of leader performance ratings given by an officer supervisor, and the ratings of two or three cadet (upperclassmen) supervisors (U.S. Corps of Cadets, 1995). Multiple regression analysis predicting cumulative MD grades across 4 years (multiple $R=.23$ ), $F(8,1141)=11.95, p<.001$, identified hardiness, transformational leadership style (Bass, 1998), and several other variables as significant independent predictors of leader performance (Bartone, 1999b; Milan, Bourne, Zazanis, \& Bartone, 2002). Personality hardiness emerged as the strongest and most consistent predictor of military development 
TABLE 2

Leadership (Military Development) Predictors, West Point, 4 Years Total

\begin{tabular}{lccc}
\hline Predictor & $\beta$ & $T$ & $p$ \\
\hline Hardiness & .15 & 5.1 & $<.00$ \\
Transformational leadership & .11 & 3.9 & $<.00$ \\
College entrance scores & .07 & 2.5 & $<.01$ \\
Social judgment & .07 & 2.3 & $<.02$ \\
Emotional stability & -.07 & -2.2 & $<.03$ \\
Extraversion & .07 & 2.0 & $<.04$ \\
Traditional values & .07 & 2.0 & \\
\hline
\end{tabular}

Note. From Bartone (1999b). Multiple regression, backward elimination, mean substitution for missing data. Model: $F(8,1141)=11.95, p<.0001$. Multiple $R=.23$.

grades for these officer cadets (Table 2). In a similar study, hardiness proved to be an even stronger predictor of leader performance for women cadets, as compared to men (Bartone \& Snook, 2000). These studies show that cadets who are high in hardiness perform more effectively as leaders, as indicated by external ratings of cadet peers and faculty supervisors. This does not indicate that they are influencing hardiness levels in their subordinates. However, it does show that cadets high in hardiness are rated more favorably on the various criteria included in the definition of effective leadership at West Point. In particular, it shows that they are admired by their subordinates. This provides a necessary (if not sufficient) condition for the hardy leader social influence process posited here.

In these cadet data, transformational leadership style (Bass, 1998; Burns, 1978) also predicts leadership performance in cadets, although not as strongly as hardiness. A subsequent correlational analysis revealed that transformational leadership is not significantly correlated with hardiness, although transformational leadership is moderately correlated with the hardiness facet of commitment. It is possible that those high in personality hardiness are more apt to develop a transformational leadership style, but that this occurs only under certain environmental or organizational conditions. This is an important question for future research to address.

Together these results indicate that Army cadets who are higher in hardiness-a characteristic sense of commitment, control, and challenge—are more effective as leaders in a military-type organization. Again, this shows that such leaders have the esteem of their subordinates, which may be a necessary precondition for hardy leader social influence to occur. To the extent that leader performance ratings also reflect performance of the groups being led, and that group performance is at least partly a function of effective coping with stress, these results also lend indirect support to the hardy leader social influence process. This is to say that the high-hardy cadet is rated as a better leader in part because he or she has aided the group to adjust and perform well under stressful conditions. 
Another study done with Norwegian Navy officer cadets also supports a hardy leader effect on groups. This study sought to identify factors that contribute to developing cohesion in squad-sized units undergoing an intense 2-week training exercise (Bartone et al., 2002). Results showed that hardiness and small unit leadership influenced cohesion levels in a positive direction, and that hardiness and leadership interacted to influence cohesion. This suggests that what leaders do, and how they are perceived by their subordinates, can have a teambuilding or cohesion-enhancing effect on the unit. An additional finding, that personality hardiness is also associated with higher cohesion levels in the wake of a stressful group experience, further suggests a sense-making mechanism for such leader effects.

The key operative power of hardiness to buffer or transform stressful experiences seems to be related to the particular interpretations of such experiences that are typically made by the hardy person. If a stressful or painful experience can be cognitively framed and made sense of within a broader perspective that holds that all of existence is essentially interesting, worthwhile, fun, a matter of personal choice, and providing chances to learn and grow, then the stressful experience can have beneficial psychological effects instead of harmful ones. In a small group context, leaders are in a unique position to shape how stressful experiences are understood by members of the group. The leader who, through example and discussion, communicates a positive construction or reconstruction of shared stressful experiences, may exert an influence on the entire group in the direction of his or her interpretation of experience. Thus, leaders who are high in hardiness likely have a greater impact in their groups under high-stress conditions, when by their example, as well as by the explanations they give to the group, they encourage others to interpret stressful events as interesting challenges that they are capable of meeting, and in any case can learn and benefit from. This process itself, as well as the positive result (a shared understanding of the stressful event as something worthwhile and beneficial) could also be expected to generate an increased sense of shared values, mutual respect, and cohesion. Further support for this interpretation comes from the regression results showing that hardiness and leadership interact to affect postexercise cohesion levels (Bartone et al., 2002). This interaction effect means that the positive influence of leaders on the growth of unit cohesion is greater when hardiness levels in the unit are high to begin with. Once again, this does not confirm a direct influence of leaders on the hardiness levels of subordinates; however, it does suggest that leaders can influence positive interpretations of stressful events within a group, and that hardiness plays a role in this process.

Several theoretical ideas from the leadership literature are also relevant to the hardy leader influence process postulated here. In a thoughtful essay on the psychology of military leadership, Gal (1987) argued that for future and more demanding military operations, military leaders are needed who can increase the 
commitment of subordinates. According to Gal, this is the central operative activity of transformational leaders; that is, to increase the overall commitment levels of subordinates. The research on hardiness and leader performance summarized earlier suggests that leaders who are high in hardiness may be especially skilled at building up this sense of commitment in subordinates, and further suggests that how experiences get interpreted (interpretations shaped by leaders) is a critical part of the process.

Another relevant leadership theory is generally referred to as transformational leadership (Bass, 1998; Burns, 1978). As elaborated by Bass (1998), transformational leadership goes beyond reward and punishment approaches, and inspires subordinates to higher levels of effort and commitment. Conceptually, it includes the four elements of idealized influence, inspirational motivation, individualized consideration, and intellectual stimulation (Bass \& Avolio, 1994). The transformational leader dimension of inspirational motivation is one of special relevance to the question of how hardy leaders might influence others in a work group. Bass and Avolio described inspirational motivation as follows:

Transformational leaders behave in ways that motivate and inspire those around them by providing meaning and challenge to their followers' work. Team spirit is aroused. Enthusiasm and optimism are displayed. The leader gets followers involved in envisioning attractive future states. The leader clearly communicates expectations that followers want to meet and also demonstrates commitment to goals and the shared vision. (p. 3)

This description makes it clear that transformational leadership is believed to work in part through some process whereby leaders generate an increased sense of meaning, commitment, and challenge among their subordinates. The process itself is not further elaborated by transformational leadership theorists. The hardy leader influence hypothesis presented here suggests a possible mechanism underlying the inspirational motivation aspect of transformational leadership.

Increasing commitment and motivation is also an important feature of path-goal leadership theory, which focuses attention on how leaders influence the motivation of subordinates by identifying significant goals, structuring situations so that subordinates experience personal rewards for goal attainment, and clarifying the pathways for achieving these desired goals (House, 1971, 1996). According to path-goal theory, leaders may demonstrate supportive, directive, participative, or achievement leadership depending on their personal style and preference, as well as the contingencies of particular situations or tasks (House $\&$ Mitchell, 1974). Most relevant to the hardy leader influence hypothesis is the achievement leadership orientation of path-goal theory. This leader is somehow able to tap into and even increase followers' motivation to surmount obstacles and achieve goals, and to orient this achievement motivation toward important 
group goals. This is very similar to what the high-hardy person does at the individual level when confronted with unexpected or highly stressful situations; he or she tends to interpret these situations as challenges to meet head-on, to learn and grow from, rather than as threats or disruptions to be avoided. Path-goal leadership theory thus provides a broader framework for understanding how high-hardy leaders might influence the motivation, thinking, and behavior of subordinates.

\section{CASE STUDY: HOW A HARDY LEADER CAN INFLUENCE GROUP HARDINESS ON MILITARY OPERATIONS}

The following case vignette is provided to illustrate how the hardy leader influence process might operate in a deployed military unit. The case is a real one, identified during research conducted in 1995 with a U.S. Army unit deployed to Saudi Arabia as part of a deterrent or peace enforcement operation. I had the opportunity to visit this unit as part of a study of deployment stress, morale, and cohesion in U.S. Army Air Defense Artillery (ADA) battalions. After the Gulf War ended in 1991, ADA battalions were stationed in Saudi Arabia and Kuwait to guard against possible Iraqi missile attacks. Units deployed for about 6 months, and then were replaced by other ADA units.

The unit under study was about 4.5 months into the mission, and things had by this time become dull and predictable for the soldiers. As the research team conducted interviews and surveys throughout the battalion, it became clear that unit morale was extremely low, as was cohesion in all the batteries or companies examined. However, morale and cohesion levels were dramatically different in one part of the battalion: the headquarters and maintenance company. Here, morale was high and cohesion was strong, in dramatic contrast to the other elements of the battalion. How could this difference be understood?

The company commander provided a ready explanation for his unit's high morale and cohesion. As he told it, shortly after they arrived in theater he put the company to work on a major task that provided a common goal, and a tangible mission to work on during their 6 months in the desert. He had heard about a nearby area that had been used as an equipment dump after the Gulf War. Tons of old military equipment and parts were buried in the sand, rusted, and dirty. The commander decided to assign his unit the task of excavating this area, and recovering, cleaning, and repairing as much equipment as possible over the course of their deployment. By the final stage of their 6-month rotation, they had salvaged over $\$ 1$ million worth of equipment from the dump, and returned it to the Army supply system in good working order. The walls of their company work area and meeting room were bedecked with photographs showing before-and-after scenes of the equipment dump. Adding to the sense of accomplishment and transformation, the soldiers had 
built a multipurpose athletic field on the former dump site, which the entire battalion was using for sports events. Regardless of rank, all unit members spoke with great pride about this accomplishment.

This small example shows how a proactive, committed, high-hardy leader might influence an entire work group in the direction of greater hardiness and stress resiliency. The company commander took creative control of an ambiguous situation, and proceeded to define a meaningful mission for his unit. He essentially created a major task, something that was challenging, that he and his troops could exercise control over; then he helped his soldiers develop a shared sense of commitment to the task. It is also noteworthy that the task he generated had a clear goal or end state that could be accomplished with the available resources and time. He got his soldiers and subordinate leaders involved in the planning and execution, and led by example throughout. This leader also knew how to capitalize on recognition and pride in accomplishment, posting pictures and progress reports, and arranging for outside recognition from senior leaders and national news media. This external recognition further contributed to an enhanced sense of positive meaning within the work group, and a shared belief that what they had done was important and valuable. Whereas other units in the same battalion languished in alienation, boredom, and powerlessness, under the same external stressful conditions this one leader was able to increase unit morale and cohesion, commitment, control, and challenge within his company. This example suggests how a high-hardy leader may be able to influence his or her entire unit toward more hardy interpretations of experience, and the positive, resilient reactions that can follow.

\section{CONCLUSIONS}

As we have seen, several theoretical formulations as well as a number of research studies lend support to the hypothesis that hardy leaders can generate increasingly "hardy" and positive shared interpretations of experience, at least in the context of highly demanding military training activities and exercises. Can this valuable leader influence apply in other circumstances as well, such as mass casualties or disasters, or modern military deployments that entail the kinds of psychological stressors outlined earlier?

Although more focused research is certainly needed to answer this question definitively, there is now sufficient evidence to justify a qualified affirmative, and to provide a preliminary profile of how the high-hardy leader behaves to influence hardiness and stress resilience in an entire unit. The prototypical hardy leader leads by example, providing subordinates with a role model of the hardy approach to life, work, and reactions to stressful experiences. Through actions and words, he or she demonstrates a strong sense of commitment, control, and 
challenge, and a way of responding to stressful circumstances that demonstrates stress can be valuable, and that stressful events always at least provide the opportunity to learn and grow. A hardy leader facilitates "hardy" group sense-making of experience, in how tasks or missions are planned, discussed, and executed, and also as to how mistakes, failures, and casualties are spoken about and interpreted. Although most of this sense-making influence occurs through normal day-to-day interactions and communications, occasionally it can happen in the context of more formal after-action reviews, or debriefings that can focus attention on events as learning opportunities and create shared positive constructions of events and responses around events. ${ }^{2} \mathrm{~A}$ hardy leader also seeks out (or creates if necessary) meaningful and challenging group tasks, and then capitalizes on group accomplishments by providing recognition, awards, and opportunities to reflect on and magnify positive results (e.g., photographs, news accounts, and other tangible mementos).

In work groups such as the military, where individuals are regularly exposed to extreme work-related stressors and hazards, leaders are in a unique position to shape how stressful experiences are made sense of, interpreted, and understood by members of the group. The leader who by example, discussion, and policies communicates a positive construction or reconstruction of shared stressful experiences, may exert an influence on the entire group in the direction of his or her interpretation of experience - toward more resilient and hardy sense making. Given the promising results seen thus far, this hardy leader influence process merits further active empirical investigation. A better knowledge and understanding of the processes underlying resilience would be of substantial value not just for military organizations, but for anyone interested in promoting resiliency and health in groups exposed to highly stressful circumstances.

\section{ACNOWLEDGMENTS}

Portions of this article appeared in Bartone, P. T. (2004). Increasing resiliency through shared sensemaking: Building hardiness in groups. In D. Paton, J. M. Violanti, C. Dunning, \& L. M. Smith (Eds.), Managing traumatic stress risk: A proactive approach (pp. 129-140). Springfield, IL: Thomas.

\footnotetext{
${ }^{2}$ A recent National Institute of Mental Health (2002) report on best practices for early psychological interventions following mass violence events noted great confusion regarding the term debriefing. The authors recommend that the term be reserved for operational after-action reviews, and not be applied to psychological treatment interventions such as critical incident stress debriefing (Mitchell \& Everly, 2000). I maintain that for groups such as the military, after-action group debriefings, properly timed and conducted and focused on events rather than emotions and reactions, can have great therapeutic value for many participants by helping them to place potentially traumatizing events in a broader context of positive meaning (Bartone, 1997).
} 


\section{REFERENCES}

Allport, G. W. (1985). The historical background of social psychology. In G. Lindzey \& E. Aronson (Eds.), Handbook of social psychology (3rd ed., Vol. 1, pp. 1-46). New York: Random House.

Bartone, P. T. (1989). Predictors of stress-related illness in city bus drivers. Journal of Occupational Medicine, 31, 657-663.

Bartone, P. T. (1993, June). Psychosocial predictors of soldier adjustment to combat stress. Paper presented at the Third European Conference on Traumatic Stress, Bergen, Norway.

Bartone, P. T. (1995, July). A short hardiness scale. Paper presented at the annual convention of the American Psychological Society, New York.

Bartone, P. T. (1996, August). Stress and hardiness in U.S. peacekeeping soldiers. Paper presented at the annual convention of the American Psychological Association, Toronto, Ontario, Canada.

Bartone, P. T. (1997). Einsatzorientierte Nachbesprechung (Debriefing): Was jeder militärische Führer wissen sollte [Event-oriented debriefing following military operations: What every leader should know]. In T. Sporner (Ed.), Streßbewältigung und Psychotraumatologie im UN- und humanitären Hilfseinsatz (pp. 126-133). Bonn, Germany: Beta Verlag.

Bartone, P. T. (1999a). Hardiness protects against war-related stress in Army reserve forces. Consulting Psychology Journal, 51, 72-82.

Bartone, P. T. (1999b, November). Personality hardiness as a predictor of officer cadet leadership performance. Paper presented at the International Military Testing Association Meeting, Monterey, CA.

Bartone, P. T. (2000). Hardiness as a resiliency factor for United States forces in the Gulf War. In J. M. Violanti, D. Paton, \& C. Dunning (Eds.), Posttraumatic stress intervention: Challenges, issues, and perspectives (pp. 115-133). Springfield, IL: Thomas.

Bartone, P. T. (2001, June). Psychosocial stressors in future military operations. Paper presented at the Cantigny Conference Series on Future of Armed Conflict, Wheaton, IL.

Bartone, P. T., Adler, A. B., \& Vaitkus, M. A. (1998). Dimensions of psychological stress in peacekeeping operations. Military Medicine, 163, 587-593.

Bartone, P. T., Johnsen, B. H., Eid, J., Brun, W., \& Laberg, J. C. (2002). Factors influencing small unit cohesion in Norwegian Navy officer cadets. Military Psychology, 14, 1-22.

Bartone, P. T., \& Snook, S. A. (2000, June). Gender differences in predictors of leader performance over time. Paper presented at the American Psychological Society convention, Miami, FL.

Bartone, P. T., Ursano, R. J., Wright, K. W., \& Ingraham, L. H. (1989). The impact of a military air disaster on the health of assistance workers: A prospective study. Journal of Nervous and Mental Disease, 177, 317-328.

Bass, B. M. (1998). Transformational leadership. Mahwah, NJ: Lawrence Erlbaum Associates, Inc.

Bass, B. M., \& Avolio, B. J. (1994). Introduction. In B. M. Bass \& B. J. Avolio (Eds.), Improving organizational effectiveness through transformational leadership (pp. 1-9). Thousand Oaks, CA: Sage.

Bell, D. B., Bartone, J., Bartone, P. T., Schumm, W. R., \& Gade, P. A. (1997). USAREUR family support during Operation Joint Endeavor: Summary report (ARI Special Rep. No. 34). Alexandria, VA: U.S. Army Research Institute for the Behavioral and Social Sciences. (DTIC No. AD-A339 016)

Berger, P. L., \& Luckmann, T. (1966). The social construction of reality. Garden City, NY: Doubleday.

Binswanger, L. (1963). Being in the world: Selected papers of Ludwig Binswanger. New York: Basic Books.

Bonanno, G. A. (2004). Loss, trauma and human resilience: Have we underestimated the human capacity to thrive after extremely aversive events? American Psychologist, 59, 20-28.

Britt, T. W., Adler, A. B., \& Bartone, P. T. (2001). Deriving benefits from stressful events: The role of engagement in meaningful work and hardiness. Journal of Occupational Health Psychology, 6, 53-63.

Burns, J. M. (1978). Leadership. New York: Harper \& Row. 
Castro, C., \& Adler, A. (1999). OPTEMPO: Effects on soldier and unit readiness. Parameters, 29, 86-95.

Contrada, R. J. (1989). Type A behavior, personality hardiness, and cardiovascular responses to stress. Journal of Personality and Social Psychology, 57, 895-903.

Florian, V., Mikulincer, M., \& Taubman, O. (1995). Does hardiness contribute to mental health during a stressful real life situation? The role of appraisal and coping. Journal of Personality and Social Psychology, 68, 687-695.

Frankl, V. (1960). The doctor and the soul. New York: Knopf.

Funk, S. C. (1992). Hardiness: A review of theory and research. Health Psychology, 11, 335-345.

Funk, S. C., \& Houston, B. K. (1987). A critical analysis of the hardiness scale's validity and utility. Journal of Personality and Social Psychology, 53, 572-578.

Gal, R. (1987). Military leadership for the 1990s: Commitment-derived leadership. In L. Atwater \& R. Penn (Eds.), Military leadership: Traditions and future trends (pp. 53-59). Annapolis, MD: U.S. Naval Academy.

Heidegger, M. (1986). Being and time. New York: HarperCollins.

Hoge, C. W., Castro, C. A., Messer, S. C., McGurk, D., Cotting, D. I., \& Koffman, R. L. (2004). Combat duty in Iraq and Afghanistan, mental health problems, and barriers to care. New England Journal of Medicine, 351, 13-22.

Horowitz, M., Wilner, N., \& Alvarez, W. (1979). Impact of Events Scale: A measure of subjective stress. Psychosomatic Medicine, 41, 209-218.

House, R. J. (1971). A path-goal theory of leader effectiveness. Administrative Science Quarterly, 16, 321-339.

House, R. J. (1996). Path-goal theory of leadership: Lessons, legacy, and a reformulated theory. Leadership Quarterly, 7, 323-352.

House, R. J., \& Mitchell, T. R. (1974). Path-goal theory of leadership. Contemporary Business, 3, 81-98.

Ingraham, L. H., \& Manning, F. J. (1981). Cohesion: Who needs it, what is it and how do we get it to them? Military Review, 61, 3-12.

Janis, I. (1982). Groupthink (2nd ed.). Boston: Houghton-Mifflin.

Jones, E., Woolven, R., Durodie, W., \& Wessely, S. (2004). Public panic and morale: A reassessment of civilian reactions during the Blitz and World War 2. Journal of Social History, 17, 463-479.

Kirkland, F. R., Bartone, P. T., \& Marlowe, D. H. (1993). Commanders' priorities and psychological readiness. Armed Forces and Society, 19, 579-598.

Kobasa, S. C. (1979). Stressful life events, personality, and health: An inquiry into hardiness. Journal of Personality and Social Psychology, 37, 1-11.

Kobasa, S. C., Maddi, S. R., \& Kahn, S. (1982). Hardiness and health: A prospective study. Journal of Personality and Social Psychology, 42, 168-177.

Maddi, S. R. (1967). The existential neurosis. Journal of Abnormal Psychology, 72, 311-325.

Maddi, S. R., \& Kobasa, S. C. (1984). The hardy executive. Homewood, IL: Dow Jones-Irwin.

Milan, L. M., Bourne, D. M., Zazanis, M. M., \& Bartone, P. T. (2002). Measures collected on the USMA class of 1998 as part of the Baseline Officer Longitudinal Data Set (BOLDS) (ARI Tech. Rep. No. 1127). Alexandria, VA: U.S. Army Research Institute for the Behavioral and Social Sciences.

Mitchell, J. T., \& Everly, G. S. (2000). Critical incident stress management and critical incident stress debriefing: Evolutions, effects, and outcomes. In B. Raphael \& J. P. Wilson (Eds.), Psychological debriefing: Theory, practice and evidence (pp. 71-90). Cambridge, England: Cambridge University Press.

National Institute of Mental Health. (2002). Mental health and mass violence: Evidence-based early psychological intervention for victims/survivors of mass violence. A workshop to reach consensus on best practices (NIH Publication No. 02-5138). Washington, DC: U.S. Government Printing Office. 
Paton, D. (1997). Managing work-related psychological trauma: An organizational psychology of response and recovery. Australian Psychologist, 32, 46-55.

Ritchie, E. C., Leavitt, F., \& Hanish, S. (2006). The mental health response to the $9 / 11$ attack on the Pentagon. In Y. Neria, R. Gross, R. Marshall, \& E. Susser (Eds.), 9/11: Mental health in the wake of a terrorist attack. New York: Cambridge University Press.

Roth, D. L., Wiebe, D. J., Fillingim, R. B., \& Shay, K. A. (1989). Life events, fitness, hardiness, and health: A simultaneous analysis of proposed stress-resistance effects. Journal of Personality and Social Psychology, 57, 136-142.

Sinclair, R. R., \& Tetrick, L. E. (2000). Implications of item wording for hardiness structure, relation with neuroticism, and stress buffering. Journal of Research in Personality, 34, 1-25.

U.S. Corps of Cadets. (1995). Leadership evaluation and developmental ratings (USCC Regulation No. 623-1). West Point, NY: U.S. Military Academy.

van Emmerik, A. A., Kamphuis, J. H., Hulsbosch, A. M., \& Emmelkamp, P. M. (2002). Single session debriefing after psychological trauma: A metaanalysis. Lancet, 360, 766-771.

Watson, P. J., Ritchie, E. C., Demer, J., Bartone, P., \& Pfefferbaum, B. J. (2006). Improving resilience trajectories following mass violence and disaster. In E. C. Ritchie, P. J. Watson, \& M. J. Friedman (Eds.), Interventions following mass violence and disaster (pp. 37-53). New York: Guilford.

Weik, K. E. (1995). Sensemaking in organizations. Thousand Oaks, CA: Sage.

Weisaeth, L., \& Sund, A. (1982). Psychiatric problems in UNIFIL and the UN-soldier's stress syndrome. International Review of Army, Air Force and Navy Medical Service, 55, 109-116.

Wessely, S. (2005). Victimhood and resilience. New England Journal of Medicine, 353, 548-550.

Westman, M. (1990). The relationship between stress and performance: The moderating effect of hardiness. Human Performance, 3, 141-155.

Wiebe, D. J. (1991). Hardiness and stress moderation: A test of proposed mechanisms. Journal of Personality and Social Psychology, 60, 89-99. 